\title{
Simple and fast microwave-assisted ruthenium_catalyzed direct aldol reaction
}

\author{
Elahe Keshavarz ${ }^{*}$ Khalil Tabatabaeian, Manouchehr Mamaghani and Nosrat O. Mahmoodi
}

Department of Chemistry, Faculty of Sciences, University of Guilan, P.O. Box 41335-1914, Rasht, Iran

\begin{tabular}{|c|c|}
\hline ART I CLE I NFO & A B S T RACT \\
\hline $\begin{array}{l}\text { Article history: } \\
\text { Received March 30, } 2012 \\
\text { Received in Revised form } \\
\text { April 5, 2012 } \\
\text { Accepted 5 April } 2012 \\
\text { Available online } \\
6 \text { April 2012 } \\
\end{array}$ & $\begin{array}{l}\text { A microwave-assisted method was developed for the synthesis of aldol adducts using } \\
\mathrm{RuCl}_{3} \cdot \mathrm{nH}_{2} \mathrm{O}-\mathrm{BINAP} \text { as an efficient catalyst. Important advantages of this technology include } \\
\text { environmentally benign condition, highly accelerated rate of the reaction with an improvement } \\
\text { in the chemoselectivity and quality of the products. }\end{array}$ \\
\hline $\begin{array}{l}\text { Keywords: } \\
\text { Aldol reaction } \\
\text { Catalyst } \\
\text { Microwave technique }\end{array}$ & \\
\hline
\end{tabular}

\section{Introduction}

$\mathrm{C}-\mathrm{C}$ bond formation is the essence of organic synthesis. An aldol reaction, represents one of the classical $\mathrm{C}-\mathrm{C}$ bond forming processes, and its variants have been used extensively in many important syntheses ${ }^{1-3}$. There has been great demand to develop one-pot procedures ${ }^{4}$ for successive reactions for the formation of several $\mathrm{C}-\mathrm{C}$ bonds. The minimization of steps involved in multistep synthesis not only allows the reduction of waste but also results in the diminution of costs. The pursuit of all these synthetic targets with increasing complexity has resulted in the development of reactions that emphasize chemo-, regio-, diastereo-, and enantioselectivity.

An asymmetric aldol reaction is one of the most common methods for $\mathrm{C}$ - $\mathrm{C}$ bond formation in organic molecules ${ }^{5}$. It is extensively applied in the synthesis of carbohydrates, amino sugars, steroids, and other valuable chiral organic compounds. It provides an atom-economic approach to $\beta$-hydroxyl 
carbonyls, which make up a large family of chiral intermediates for the synthesis of biologically active substances and natural products ${ }^{6-10}$.

The development of a direct catalytic asymmetric aldol reaction, in which the pre-activation of nucleophiles is no longer needed, has been worthy of notice.

On the other hand, metal-catalyzed reactions have made a great contribution to the recent growth of organic synthesis and a variety of synthetic methods have been reported using transition metal complexes in catalytic amounts ${ }^{11-13}$. Among the transition metal Lewis acids, $\mathrm{Ru}^{\mathrm{III}}$ salts are known to catalyze a variety of organic transformations, and the investigation of the chemistry of ruthenium continues to be an active area of organometallic chemistry ${ }^{14,15}$.

Here, we report a direct aldol reaction of ketones and aromatic aldehydes catalyzed by $\mathrm{RuCl}_{3} \cdot \mathrm{nH}_{2} \mathrm{O}$ and chiral ligand under microwave condition.

\subsection{Results and Discussion}

The aldol reaction is one of the most important chemical reactions. Substantial effort has gone into its development using preformed enolates, resulting in a remarkable level of regio- and stereochemical control. In all of the catalytic asymmetric reactions, preconversion of the ketone moiety to a more reactive species is an unavoidable necessity. Thus, the development of a direct catalytic asymmetric aldol reaction is highly desirable in terms of atom economy.

In continuation of our research in environmentally benign ${ }^{16-18}$ and microwave-assisted conditions $^{19}$, we now report an operationally simple and fast method for the preparation of aldol products by one-pot condition reaction. We have previously reported this work ${ }^{17}$ at room temperature that in all cases, the reaction produced the aldol products with longer reaction times $(0.5-2.5 \mathrm{~h}) . \mathrm{In}$ this research, We decided to overcome the problem of somehow prolonged reaction times using microwave irradiation. Therefore, the direct aldol reaction of ketones with aromatic aldehydes using catalytic amount of $\mathrm{RuCl}_{3} \cdot \mathrm{nH}_{2} \mathrm{O}$ and chiral ligand (BINAP) was irradiated in a $160 \mathrm{~W}$ microwave oven and proceeded smoothly to give the corresponding aldol adducts in good yields with moderate to good diastereoselectivity.

The reaction of propiophenone $(1.5 \mathrm{mmol})$ and aldehyde $(0.25 \mathrm{mmol})$ in a minimum amount of solvent was carried out in the presence of BINAP/ $\mathrm{Ru}^{\mathrm{III}}$ chloride $(0.010 / 0.009 \mathrm{mmol})$. Typical results of the aldol reactions, under optimized reaction conditions, are shown in Table 1.

Next, we examined the reaction of cyclopentanone as an enolate source under the same condition described in entries 5 and 6 of Table 1.
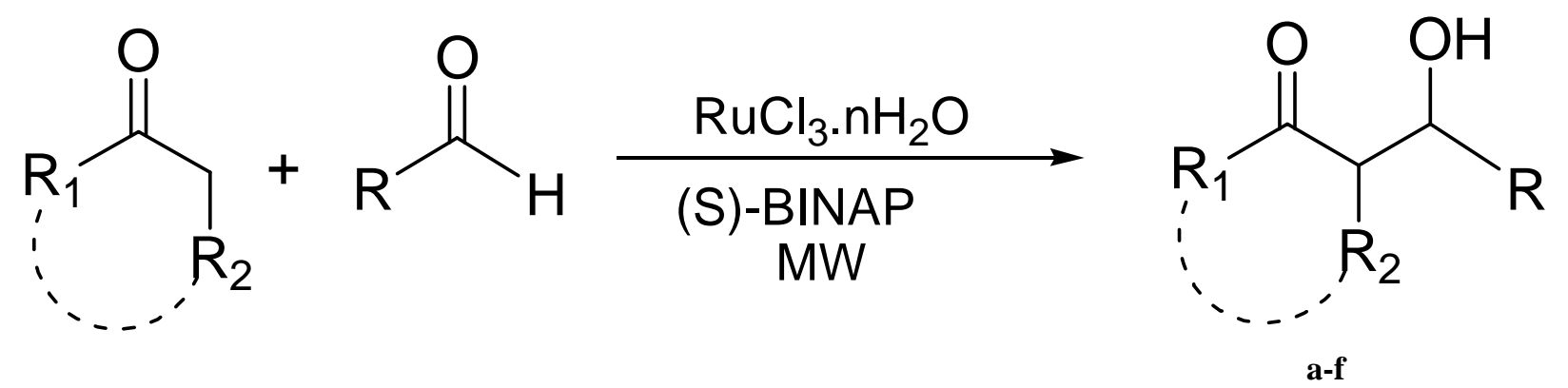

Scheme 1 
Table 1. Microwave-assisted ruthenium-catalyzed cross aldol reactions of aldehydes with ketones

\begin{tabular}{|c|c|c|c|c|c|c|}
\hline Entry $^{\mathrm{a}}$ & Ketone & $\mathrm{R}$ & Product ${ }^{\mathrm{c}}$ & Yield $^{\mathrm{b}}(\%)$ & Time (min) & d. r. (syn:anti) ${ }^{\mathrm{c}}$ \\
\hline 1 & Propiophenone & $4-\mathrm{O}_{2} \mathrm{NC}_{6} \mathrm{H}_{4-}$ & $\mathbf{a}$ & 77 & 2 & $47: 53$ \\
\hline 2 & Propiophenone & $2-\mathrm{O}_{2} \mathrm{NC}_{6} \mathrm{H}_{4}-$ & b & 80 & 7 & $46: 54$ \\
\hline 3 & Propiophenone & $4-\mathrm{FC}_{6} \mathrm{H}_{4-}$ & C & 69 & 5 & $68: 32$ \\
\hline 4 & Propiophenone & $\mathrm{C}_{6} \mathrm{H}_{5^{-}}$ & d & 72 & 5 & $60: 40$ \\
\hline 5 & Cyclopentanone & $4-\mathrm{O}_{2} \mathrm{NC}_{6} \mathrm{H}_{4}-$ & e & 72 & 5 & $67: 33$ \\
\hline 6 & Cyclopentanone & $2-\mathrm{O}_{2} \mathrm{NC}_{6} \mathrm{H}_{4}-$ & $\mathbf{f}$ & 65 & 5 & $60: 40$ \\
\hline
\end{tabular}

A mechanistic pathway for the catalytic aldol reaction is proposed. Initially, ketone may be captured on the ruthenium complex by the synergic action (i) to form the corresponding rutheniumenolate (ii) which reacts with aldehyde (iii) to give the ruthenium-aldolate (iv). Finally, when ketone is incorporated, the aldol product is released to regenerate the intermediate ruthenium-enolate (ii). The chiral space derives from the conformational preferences of the BINAP moiety. The absolute configuration in many cases was assigned by comparison with the literature and assumed to be the same in the other cases.

\section{Conclusions}

We have developed a mild and efficient direct aldol reaction using simple substrates in the presence of $\mathrm{RuCl}_{3} \cdot \mathrm{nH}_{2} \mathrm{O}$-BINAP. Microwave technique offers clean, fast, and economic for the synthesis of aldol adducts ${ }^{22}$. Retro aldol reactions and self-condensation of aldehydes were prevented as well. Work is currently ongoing to develop an asymmetric variant of the reaction through incorporation of the other chiral system. Additionally, we have begun to explore the use of esters in the context of several aldol reactions.

\section{Experimental}

All solvents, organic and inorganic compounds were purchased from Merck and Fluka and used without further purification. All reactions were followed by TLC with detection by UV light. The isolation of pure products was carried out via preparative thin layer chromatography (silica gel 60 $\mathrm{GF}_{254}$, Merck). IR spectra were recorded on Shimadzu FTIR-8400S spectrometer. ${ }^{1} \mathrm{H}$ NMR spectra were obtained on a Bruker DRX-500 Avance spectrometer and ${ }^{13} \mathrm{C}$ NMR spectra were obtained on a Bruker DRX-125 Avance spectrometer. Samples were analyzed in $\mathrm{CDCl}_{3}$, and the chemical shift values are reported in ppm relative to TMS (tetramethylsilane) as the internal reference.

\section{Typical procedure for ruthenium-catalyzed aldol reaction}

A mixture of aldehyde $(0.25 \mathrm{mmol})$, ketone $(1.5 \mathrm{mmol}), \mathrm{RuCl}_{3} \cdot \mathrm{nH}_{2} \mathrm{O}(0.009 \mathrm{mmol}),(\mathrm{S})$-BINAP $(0.010 \mathrm{mmol})$ and $\mathrm{KOH}(0.15 \mathrm{mmol})$ in a minimum amount of dioxane was irradiated in a $160 \mathrm{~W}$ microwave oven and monitored by TLC. After the indicated reaction time, the reaction mixture was purified by thin layer chromatography (silica gel, EtOAc-petroleum ether, 5:12) providing the aldol adduct.

\section{Acknowledgements}

This work was supported in part by the University of Guilan Research Council.

\section{References}

1. Tabatabaeian K., Heidari H., Mamaghani M., Mahmoodi N. O. (2012) Ru(II) Complexes Bearing Tertiary Phosphine Ligands: A Novel and Efficient Homogeneous Catalyst for One-pot Synthesis 
of Dihydropyrano [3,2-c] Chromene and Tetrahydrobenzo [b] pyran Derivatives. Appl. Organomet. Chem., 26(2), 56-61.

2. Delas C., Moïse C. (2000) A Combination of Allyltitanation and Tandem Aldol-Tischtschenko Reactions using Tetraisopropoxytitanium. Synthesis, 2, 251-254.

3. Geary L. M., Hultin P. G. (2009) The State of the Art in Asymmetric Induction: the Aldol Reaction as a Case study. Tetrahedron: Asymmetry, 20(2), 131-173.

4. Chaskar A. (2012) Phosphomolybdic Acid Accelerated One-pot Synthesis of 1-Aryl-1H, 3Hthiazolo[3, 4-a]benzimidazoles. Curr. Chem. Lett., 1(1), 21-26.

5. Miura T., Ina M., Imai K., Nakashima K., Masuda A., Tada N., Imai N., Itoh A. (2011) $\beta$ Aminosulfonamide-catalyzed Direct Asymmetric Aldol Reaction in Brine. Synlett, 3, 410-415.

6. Chandrasekhar S., Johny K., Reddy C. R. (2009) Proline-threonine Dipeptide as an Organocatalyst for the Direct Asymmetric Aldol Reaction. Tetrahedron: Asymmetry, 20(15), 1742-1745.

7. Rani R., Peddinti R. K. (2010) Camphor-10-sulfonamide-based Prolinamide Organocatalyst for the Direct Intermolecular Aldol Reaction between Ketones and Aromatic Aldehydes.

Tetrahedron: Asymmetry, 21(7), 775-779

8. Chen F., Huang S., Zhang H., Liu F., Peng Y. (2008) Proline-based Dipeptides with two Amide units as Organocatalyst for the Asymmetric Aldol Reaction of Cyclohexanone with Aldehydes. Tetrahedron, 64(40), 9585-9591.

9. Siyutkin D. E., Kucherenko A. S., Zlotin S. G. (2009) Hydroxy- $\alpha$-amino Acids Modified by Ionic Liquid Moieties: Recoverable Organocatalysts for Asymmetric Aldol Reactions in the Presence of Water. Tetrahedron, 65(7), 1366-1372.

10. Tzeng Z.-H., Chen H.-Y., Reddy R. J., Huang C.-T., Chen K. (2009) Highly Diastereo- and Enantioselective Direct Aldol Reactions Promoted by Water-compatible Organocatalysts Bearing a Pyrrolidinyl-camphor Structural Scaffold. Tetrahedron, 65(15), 2879-2888.

11. Masters C. (1981) Homogeneous Transition Metal Catalysis-a gentle Art, Chapman and Hall Ltd.

12. Meijere A. D., Diederich F. Metal-catalyzed Cross-coupling Reactions, Vol. 2, 2nd edn. Wiely$\mathrm{VCH}, \mathrm{New}$ York.

13. Dou X.-Y., Wang J.-Q., Du Y., Wang E., He L.-N. (2007). Guanidinium Salt Functionalized PEG: An Effective and Recyclable Homogeneous Catalyst for the Synthesis of Cyclic Carbonates from $\mathrm{CO}_{2}$ and Epoxides under Solvent-free Conditions. Synlett, 19, 3058-3062.

14. Murahashi S.-I. (2004) Ruthenium in Organic Synthesis, Wiely-VCH: New York.

15. Murai S. (1999) Activation of Unreactive Bonds and Organic Synthesis, Springer.

16. Tabatabaeian K., Mamaghani M., Mahmoodi N. O., Keshavarz E. (2010) Facile Access to Aldol Products from Aromatic and Heteroaromatic Aldehydes using Ruthenium Catalyst. Int. J. Inorg. Chem., ID 621376, 4 pages.

17. Tabatabaeian K., Keshavarz E., Mamaghani M., Mahmoodi N. O. (2010) An Efficient $\mathrm{Ru}^{\mathrm{III}} /$ BINAP Catalytic System for the Aldol Reactions of Ketones with Various Aldehydes. Arkivoc IX, 155-162.

18. Tabatabaeian K., Keshavarz E., Mamaghani M., Mahmoodi N. O. (2011) $\mathrm{RuCl}_{3} \cdot \mathrm{nH}_{2} \mathrm{O}$ as Catalyst for Diastereoselective Direct Aldol Reaction: An Efficient Route to Hormone Steroid Derivatives. Org. Chem. Int., ID, 325291, 5 pages.

19. Tabatabaeian K., Mamaghani M., Mahmoodi N. O., Keshavarz E. (2009) Ruthenium-catalyzed Cross Aldol Reaction with Aldehydes and Ketones. Arkivoc II, 68-75.

20. Wei H.-X., Jasoni R. L., Shao H., Hu J., Pare P. W. (2004) Anti-Selective and Regioselective Aldol Addition of Ketones with Aldehydes using $\mathrm{MgI}_{2}$ as Promoter. Tetrahedron, 60(51), 1182911835.

21. Inoue H., Kikuchi M., Ito J.-I., Nishiyama H. (2008) Chiral Phebox-rhodium Complexes as Catalysts for Asymmetric Direct Aldol Reaction. Tetrahedron, 64(3), 493-499.

22. Keshavarz E., Tabatabaeian K., Mamaghani M., Mahmoodi N. O. (2011) Simple and Fast Ruthenium Catalyzed Direct Aldol Reaction: Scope and Limitations. 15th International Electronic Conference on Synthetic Organic Chemistry, (ECSOC-15). 